\title{
Introduction of off-pump coronary artery bypass into aortic arch aneurysm repair: $A$ new solution for the surgical treatment of multiorgan arteriosclerosis
}

Hitoshi Yokoyama, MD, PhD, Yoichi Sato, MD, Shinya Takase, MD, Koki Takahashi, MD, Hiroki Wakamatsu, MD, and Yoshiyuki Sato, MD, Fukushima, Japan

$\mathrm{T}$ he simultaneous operation of aortic arch repair (AAR) and coronary artery bypass grafting has been associated with considerable operative morbidity and mortality. ${ }^{1-3}$ This combined procedure has been considered inevitable, with prolonged myocardial ischemia and cardiopulmonary bypass (CPB) time, which are significant risk factors for adverse outcome in aortic arch surgery. ${ }^{2}$ Appropriate myocardial protection is also mandatory to avoid perioperative myocardial failure.

Recent technical improvements in off-pump coronary artery bypass (OPCAB) encouraged us to introduce OPCAB into this simultaneous operation to minimize the period of myocardial ischemia and CPB for improved surgical outcome in these patients with multiorgan arteriosclerosis.

\section{Patients}

From November 1999 through June 2004, 16 patients underwent the simultaneous operation of OPCAB and AAR. There were 15 (94\%) male patients and 1 female patient, with an average age of $70 \pm 7$ years (range, 62-80 years). All patients had atherosclerotic aortic arch aneurysm and major coronary artery stenosis, with comorbidities such as hypertension (100\%), left ventricular hypertrophy (56\%), and old cerebral infarction (63\%).

\section{Operative Techniques}

Time course of the combined procedure. For better understanding of the combined procedure of coronary artery bypass grafting and $\mathrm{AAR}$, the comparison of time course in the conventional procedure and $\mathrm{OPCAB}$ with AAR is presented in Figure 1.

OPCAB. After median sternotomy, a deep pericardial suture and heart retractor (Starfish; Medtronic Inc, Minneapolis, Minn)

From the Department of Cardiovascular Surgery, Fukushima Medical University School of Medicine, Fukushima, Japan.

Received for publication Aug 2, 2004; accepted for publication Aug 10, 2004.

Address for reprints: Hitoshi Yokoyama, MD, PhD, Department of Cardiovascular Surgery, Fukushima Medical University School of Medicine, 1 Hikarigaoka, Fukushima 960-1295, Japan (E-mail: hitoshiy@fmu. ac.jp).

J Thorac Cardiovasc Surg 2005;129:935-6

$0022-5223 / \$ 30.00$

Copyright (C) 2005 by The American Association for Thoracic Surgery doi:10.1016/j.jtcvs.2004.08.009

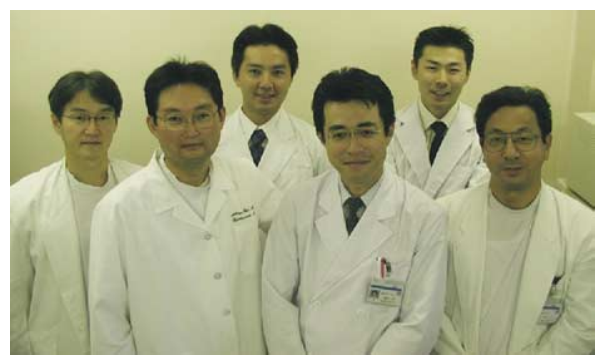

TO COME?

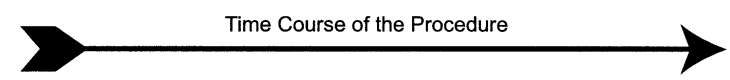

(A) $C A B G+A A R$ Antegrade cerebral perfusion

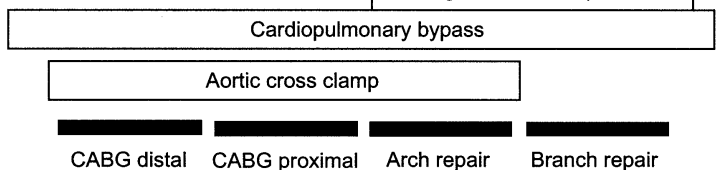

(B) $O P C A B+A A R$

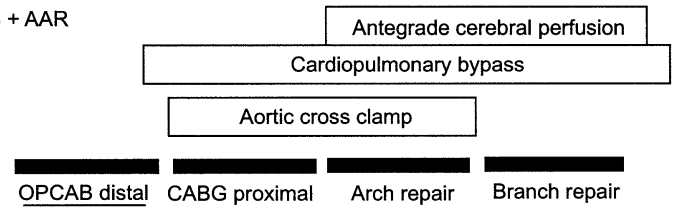

Figure 1. Time course in the combined procedure of coronary artery revascularization and AAR. A, Coronary artery bypass grafting (CABG) on the arrested heart and AAR. B, OPCAB and AAR. Note the period of CPB and aortic crossclamping (myocardial ischemia time) are shorter in $B$ than in $A$.

were used for the exposure of the coronary arteries. The coronary artery anastomosis was constructed with a running 7-0 monofilament suture, with the aid of an Octopus stabilizer (Medtronic Inc), a $\mathrm{CO}_{2}$ blower, and an intraluminal shunt. ${ }^{4}$

AAR with antegrade cerebral perfusion. CPB was established with right atrial drainage and artery perfusion through the bilateral axillary and femoral artery. During the core cooling and aortic crossclamping periods, the antegrade cold blood cardioplegic solution was delivered through the aortic root, as well as the preattached coronary artery bypass grafts. The proximal end of the coronary artery graft was attached on the ascending aorta, followed by intermittent antegrade and retrograde delivery of cardioplegic solution. The open distal anastomosis with a 4-branched Dacron graft was performed under antegrade cerebral perfusion through the left carotid and bilateral axillary arteries at a body temperature of $25^{\circ} \mathrm{C}$. Distal body perfusion was restarted through the branched graft. After the proximal graft-ascending aorta anastomosis, the arch graft was declamped to cease the myocardial ischemia. The left subclavian, left common carotid, and brachiocephalic arteries were reattached to the branched graft, followed by weaning from CPB. 
TABLE 1. Intraoperative and postoperative data $(n=16)$

\begin{tabular}{lc}
\hline Variables & \\
\hline No. of coronary artery anastomoses & $1.5 \pm 0.8(1 \sim 3)$ \\
Type of graft: SVG/RA/ITA & $11 / 10 / 1$ \\
Cardiopulmonary bypass time (min) & $243 \pm 35(187 \sim 303)$ \\
$\quad>300$ min & $1(6 \%)$ \\
Myocardial ischemic time (min) & $136 \pm 24(99 \sim 178)$ \\
$\quad>180$ min & 0 \\
Lowest rectal temperature $\left({ }^{\circ} \mathrm{C}\right)$ & $23 \pm 2(19 \sim 25)$ \\
Perioperative myocardial infarction & 0 \\
Peak CK-MB (U/L) & $36 \pm 20(12 \sim 80)$ \\
Early graft patency & $96 \%(22 / 23)$ \\
Prolonged respiratory support $(>3 \mathrm{~d})$ & $5(31 \%)$ \\
Neurologic dysfunction & $3(19 \%)$ \\
$\quad$ Transient & 0 \\
Permanent & 0 \\
Early ( $<30$ d) death & $1(6 \%)$ \\
In-hospital death &
\end{tabular}

Data are expressed as means \pm SD (range) unless otherwise stated. SVG, Saphenous vein graft; $R A$, radial artery; ITA, internal thoracic artery; $C K-M B$, creatinine kinase myocardial band.

\section{Results}

The patient's intraoperative and postoperative data are shown in Table 1. Five (31\%) patients had multivessel coronary artery bypasses. Fifteen (94\%) patients had a CPB time of shorter than 300 minutes. All patients had a myocardial ischemic time of shorter than 180 minutes. There was no perioperative myocardial failure, new myocardial infarction, or permanent neurologic dysfunction. The median intensive care unit stay was 4 days. There was no early ( $<30$ days) operative mortality. One patient with chronic renal failure died of gastrointestinal bleeding during hemodialysis, resulting in an in-hospital mortality of $6 \%$.

\section{Discussion}

The introduction of OPCAB to AAR with coronary artery revascularization has 3 major advantages.

First, this novel technique can minimize the myocardial ischemic time to decrease the risk of postoperative myocardial failure when compared with the conventional operation, in which distal coronary anastomoses are produced on the arrested heart during myocardial ischemia.

Second, the cardioplegic solution can be delivered through the preattached coronary artery bypass grafts into the myocardium, which is supplied by stenotic or obstructed coronary arteries. Superior myocardial protection is mandatory for the hypertrophied hearts, as frequently seen in these patients with longstanding hypertension.

Third, this technique can minimize the CPB time, as seen in Figure 1. Recently, Kazui and colleagues, ${ }^{5}$ using multivariate analysis, reported that a CPB time of longer than 300 minutes is an independent determinant of in-hospital mortality in total arch replacement with antegrade selective cerebral perfusion. In our study, the longest CPB time was 302 minutes in a patient with triple-vessel disease. All the other patients (94\%) had CPB times of shorter than 300 minutes, decreasing the risk of morbidity, such as prolonged respiratory support and intensive care unit stay or neurologic dysfunction. We speculate that this new technique would be more beneficial for patients with multivessel coronary artery disease who require longer periods of coronary artery anastomosis.

In conclusion, our preliminary experience demonstrated that the introduction of OPCAB to the simultaneous operation of AAR and coronary revascularization can be performed feasibly and with a satisfactory surgical outcome in these elderly patients with the complication of multiorgan atherosclerotic lesions.

\section{References}

1. Crawford ES, Svensson LG, Coselli JS, Safi HJ, Hess KR. Surgical treatment of aneurysm and/or dissection of the ascending aorta, transverse aortic arch, and ascending aorta and transverse aortic arch. J Thorac Cardiovasc Surg. 1989;98:659-74.

2. Ehrlich MP, Ergin MA, McCullough JN, Lansman SL, Galla JD, Bodian CA, et al. Predictors of adverse outcome and transient neurological dysfunction after ascending aorta/hemiarch replacement. Ann Thorac Surg. 2000;69:1755-63.

3. Yokoyama H. Aortic arch aneurysm complicated with coronary artery disease: still a surgical challenge? Ann Thorac Cardiovasc Surg. 2002; 8(2):62-8.

4. Yokoyama H, Takase S, Misawa Y, Takahashi K, Sato Y, Satokawa H. A simple technique of introducing shunts for off-pump coronary artery bypass surgery. Ann Thorac Surg. 2004;78:352-4.

5. Kazui T, Washiyama N, Muhhamad BAH, Terada H, Yamashita K, Takinami M, et al. Total arch replacement using aortic arch branched grafts with the aid of antegrade selective cerebral perfusion. Ann Thorac Surg. 2000;70:3-9. 